\title{
O PAPEL DA ADVOCACIA PÚBLICA NO DEVER DE COERÊNCIA NA ADMINISTRAÇÃO PÚBLICA
}

\author{
Rafael Carvalho Rezende Oliveira ${ }^{1}$
}

RESUMO: O artigo aborda o papel da advocacia pública na efetivação do dever de coerência da Administração Pública. O Estado Pós-moderno, fortemente marcado pela complexidade, pluralidade e incerteza, acarreta para o gestor público o desfaio de reduzir a insegurança jurídica e dispensar tratamento isonômico aos administrados. A efetividade do princípio da segurança jurídica e da garantia de coerência estatal depende da melhoria da gestão pública, mas, também, da organização e da autonomia da advocacia pública. Destacada no texto constitucional como função essencial à Justiça, a advocacia pública é responsável pelo controle interno e defesa da juridicidade dos atos estatais, garantindo aos administrados uma gestão pública dentro dos parâmetros fixados no ordenamento jurídico. A atuação coerente e isonômica da Administração Pública, evitando a edição de atos contraditórios e o tratamento desigual entre pessoas inseridas em contextos semelhantes, depende, em larga medida, da atuação do advogado público que, por essa razão, deve ter assegurada a sua independência funcional. No exercício de sua missão institucional, a advocacia pública deve zelar pela coerência administrativa, o que revela a necessidade de emissão de pareceres e outras formas de manifestação jurídica, inclusive na esfera judicial, que garantam o respeito aos precedentes judiciais e administrativos.

Palavras-Chave: Advocacia pública; Estado Pós-moderno; Administração Pública; coerência estatal.

Abstract: The article deals with the role of public advocacy in the implementation of the duty of coherence of the Public Administration. The Postmodern State, strongly marked by complexity, plurality and uncertainty, causes the public manager the task of reducing legal uncertainty and dispensing

\footnotetext{
${ }^{1}$ Doutor em Direito pela UVA-RJ. Professor Titular de Direito Administrativo do IBMEC. Professor do Programa de Pós-graduação Stricto Sensu em Direito - Mestrado e Doutorado (PPGD/UVA). Professor de Direito Administrativo da EMERJ e do curso FORUM. Professor dos cursos de Pós-Graduação da FGV e Cândido Mendes. Membro do Instituto de Direito Administrativo do Estado do Rio de Janeiro (IDAERJ). Ex-Defensor Público Federal. E-mail: rafael.caoliveira@pgm.rio.rj.gov.br. ORCID: 0000-0002-8823-1393 (disponível em https://orcid.org/0000-0002-8823-1393).
} 
with isonomic treatment to the administered. The effectiveness of the principle of legal certainty and the guarantee of state coherence depends on the improvement of public management, but also on the organization and autonomy of public advocacy. Highlighted in the constitutional text as an essential function of Justice, public advocacy is responsible for internal control and defense of the legality of state acts, guaranteeing the public administration a management within the parameters set in the legal system. The coherent and isonomic action of the Public Administration, avoiding the publication of contradictory acts and the unequal treatment between persons inserted in similar contexts, depends, to a large extent, on the performance of the state attorney that, for that reason, must have ensured the functional independence. In the exercise of its institutional mission, public advocacy must ensure administrative coherence, which reveals the need for issuing opinions and other forms of legal expression, including in the judicial sphere, that guarantee respect for judicial and administrative precedents.

KeYWORDS: Public advocacy; Postmodern State; Public administration; state coherence.

\section{INTRODUÇÃO}

O presente estudo tem por objetivo analisar o papel da atuação da advocacia pública na garantia do dever de coerência estatal.

Com as intensas transformações tecnológicas, o pluralismo de interesses consagrados no ordenamento jurídico, o excesso de informações e o incremento das incertezas e dos riscos, revela-se desafiadora a atuação coerente do gestor público. A coerência estatal é uma exigência que decorre, automaticamente, dos princípios da segurança jurídica, da boa-fé, da proteção da confiança legítima e da isonomia.

O desafio é a busca da coerência no ambiente de caos. Não se trata de exigir, pura e simplesmente, a petrificação da ação estatal, uma vez que a coerência não significa imutabilidade.

Em verdade, o caminho é a atuação estatal coerente com as promessas firmes, com as interpretações e com os próprios atos passados, com o objetivo de gerar previsibilidade para os cidadãos e, desta forma, proteger as legítimas expectativas geradas, sem proibir, contudo, as mudanças, adaptações e evoluções que são necessárias para que o Direito se mantenha conectado com as necessidades da sociedade.

Nesse contexto, revela-se conveniente investigar o papel da advocacia pública na implementação do dever de coerência na gestão pública. 


\section{Os Desafios da Gestão Pública no Estado Pós-Moderno}

A gestão pública, na atualidade, enfrenta enormes desafios, com destaque para dificuldade de compatibilizar interesses diversos, típicos de uma sociedade plural, no contexto de incertezas e constantes transformações tecnológicas.

Os desafios apresentados pela pós-modernidade, ${ }^{2}$ especialmente o incremento do risco, da velocidade da informação, das novas tecnologias e da complexidade dos interesses que devem ser satisfeitos pelo Estado, demonstram a insuficiência dos modelos tradicionais de organização, de atuação e de controle da Administração Pública, pautados por formalidades excessivas e pela despreocupação com a eficiência estatal. Igualmente, a globalização impõe a revalorização dos mercados e a necessidade de diálogos transnacionais, relativizando as fronteiras jurídicas dos Estados.

Neste cenário de complexidade, André-Jean Arnaud (2007, p. 307) demonstra o afastamento de algumas armadilhas positivistas, tais como: "determinismo (tudo pode ser explicado independentemente do observador), princípio do terceiro excluído (tudo que não é verdadeiro é falso) e reducionismo (tudo é redutível a elementos simples)".

Da mesma forma, Paolo Grossi (2007, p. 64 e 69), professor de História do Direito da Universidade de Florença, vai criticar as "mitologias da modernidade", especialmente o reducionismo do Direito que, ao pretender tornar a paisagem jurídica simples e harmoniosa, gerou a abstração e a artificiosidade. Em sua visão, o ordenamento jurídico pressupõe a realidade ordenada e não pode prescindir, portanto, do respeito à complexidade e à pluralidade social.

Há uma clara tendência à descentralização do poder no interior da organização administrativa e para fora dela, sendo possível diagnosticar, como demonstrado por Santi Romano (2008), uma pluralidade dos ordenamentos jurídicos.

O gestor público não pode ignorar as mutações sociais, políticas e jurídicas, devendo adaptar-se às novas exigências do mundo globalizado e complexo. Por esta razão, no cenário brasileiro, a Administração Pública deve reforçar a legitimidade e a eficiência de suas ações.

No contexto do ordenamento plural, caracterizado pela complexidade e, eventualmente, pelo antagonismo dos interesses que devem ser perseguidos pelo Estado, a ação administrativa deve intensificar a sua preocupação com o planejamento, com transparência, a abertura à participação da sociedade, com a

\footnotetext{
${ }^{2}$ Conforme destacado por Jacques Chevalier (2009, p. 17; 182), a sociedade contemporânea seria marcada pela complexidade, desordem, indeterminação e incerteza. O direito, por sua vez, seria plural, negociado, flexível e reflexivo. Não há consenso sobre a superação da modernidade, motivo pelo qual é possível encontrar autores que preferem fazer alusão à modernidade "tardia", "reflexiva" ou "líquida", ao invés de pós-modernidade. Sobre o tema, vide Anthony Giddens (2002), Ulrich Beck (2001) e Zygmunt Bauman (2001).
} 
prestação de contas e com instrumentos eficazes de controle pautados nos resultados.

Destaca-se, aqui, a necessidade de estabelecer coerência na ação administrativa, com o objetivo de reduzir a insegurança jurídica e dispensar tratamento isonômico aos administrados.

Infelizmente, a preocupação com a coerência da atuação estatal, embora apresente alguns avanços normativos, ainda não foi internalizada na prática de diversos órgãos, inclusive no âmbito do Poder Judiciário. ${ }^{3}$

Não é tarefa fácil decidir em cenário de complexidade, pluralidade e incerteza.

O gestor público se depara com dificuldades intensificadas em razão da necessidade de decidir de forma célere e eficiente, levando em consideração o contexto apresentado.

Não bastasse a dificuldade de encontrar a melhor decisão possível diante das inúmeras alternativas apresentadas no momento decisório, o gestor encontra, ainda, a preocupação de não ser responsabilizado posteriormente perante os órgãos de controle.

As decisões administrativas, com alguma frequência, são questionadas pelos órgãos de controle que, infelizmente, pretendem impor a visão do controlador como a única correta, sem considerar a razoabilidade das interpretações administrativas colocadas ao gestor no momento da tomada da decisão.

A confusão entre o "erro administrativo", inerente a qualquer atividade humana, inclusive aquela desenvolvida no âmbito da Administração Pública, e a configuração do "ato de improbidade administrativa", que pressupõe a atuação dolosa ou, excepcionalmente, culposa, do agente desonesto, tem sido empreendida por membros dos órgãos de controle na propositura de ações judiciais e na aplicação de sanções.

É inerente ao Estado Democrático de Direito o exercício do controle da Administração Pública, com a garantia da autonomia institucional dos órgãos controladores internos e externos.

O que deve ser evitado - e o desafio é a fixação do ponto de equilíbrio - é o olhar formalista, descontextualizado, desproporcional e substitutivo do órgão controlador sobre a decisão do gestor público, sob pena de a visão punitivista gerar a denominada "Administração Pública do medo", com a paralisia administrativa, violadora do princípio constitucional da eficiência, em razão do

\footnotetext{
${ }^{3}$ Mencione-se, por exemplo, a relutância dos juízes em observar os precedentes vinculantes, conforme demonstrou a pesquisa realizada em 2018 pela Associação dos Magistrados Brasileiros (AMB), que revelou que, na opinião da maioria dos juízes de primeiro e segundo graus, bem como dos Ministros dos Tribunais Superiores, os magistrados deveriam ter liberdade para decidir sem se pautarem, necessariamente, pelo sistema de súmulas e precedentes vinculantes. Fonte: Associação dos Magistrados Brasileiros - AMB. QUEM SOMOS. A MAGISTRATURA QUE QUEREMOS. Rio de Janeiro, novembro de 2018. Disponível em: <www.cnj.jus.br/images/pesquisas-judiciarias/Publicacoes/ 100_maiores_litigantes.pdf $>$. Acesso em: 28 abr. 2019.
} 
temor dos agentes públicos inseridos nos cargos e nas funções de direção da Administração Pública.

$\mathrm{O}$ incremento das normas jurídicas com textura aberta, especialmente os princípios jurídicos e as regras que consagram conceitos jurídicos indeterminados, fomenta a liberdade (discricionariedade regrada) do gestor para a tomada das decisões administrativas.

O caminho, no entanto, é de mão dupla: ao mesmo tempo em que há um nítido incremento do prestigio da atividade exercida pela Administração Pública na concretização das normas constitucionais, o princípio da juridicidade ${ }^{4}$ gera, naturalmente, restrições mais sensíveis à atuação do administrador e amplia o controle externo dos atos administrativos.

Revela-se, portanto, fundamental que o gestor público, de um lado, tenha incentivos ou, ao menos, não tenha medo de tomar decisões, com a preocupação de manter a coerência perante os administrados, o que preserva a segurança jurídica e a isonomia no tratamento de questões semelhantes.

Com o objetivo de garantir maior segurança jurídica na aplicação das normas de Direito Público, a Lei 13.655/2018 inseriu importantes dispositivos normativos na Lei de Introdução às Normas do Direito Brasileiro (LINDB), que podem ser divididos em, pelo menos, quatro pilares:

a) reforço da motivação da decisão estatal com ênfase no pragmatismo jurídico (arts. 20 a 24 da LINDB): com o objetivo de levar a realidade a sério, o contexto e as consequências da decisão devem ser ponderados pelos gestores e órgãos de controle;

b) proteção dos agentes públicos honestos (arts. 22 e 28 da LINDB): na interpretação de normas sobre gestão pública, serão considerados os obstáculos e as dificuldades reais do gestor e as exigências das políticas públicas a seu cargo, restringindo a responsabilização pessoal do agente público por suas decisões ou opiniões técnicas aos casos de dolo ou erro grosseiro; ${ }^{5}$

c) consensualidade e participação (arts. 26, 27 e 29 da LINDB): viabilidade da celebração de compromissos (acordos) administrativos e a possibilidade de realização de consultas públicas para edição de atos normativos;

\footnotetext{
${ }^{4}$ Conforme afirmamos em outra oportunidade, a consagração do princípio da juridicidade não aceita a ideia da Administração vinculada exclusivamente às regras prefixadas nas leis, mas sim ao próprio Direito, o que inclui as regras e princípios previstos na Constituição (OLIVEIRA, 2010).

${ }^{5}$ A exigência de dolo ou culpa para responsabilização do agente público, na forma do art. 28 da LINDB, pode gerar dúvidas quanto à suposta violação ao art. $37, \S 6^{\circ}$ da CRFB. De nossa parte, não vislumbramos ofensa ao texto constitucional na gradação da culpa, por parte do legislador ordinário, para responsabilização pessoal do agente público, notadamente pela razoabilidade da restrição (OLIVEIRA, 2019, p. 806). Frise-se que a exigência de, ao menos, culpa grave (ou erro grosseiro) já era consagrada no STJ para configuração, por exemplo, do ato de improbidade administrativa que causa lesão ao erário, com fulcro no art. 10 da Lei 8.429/1992 (lesão ao erário), sem olvidar que para os demais atos de improbidade a comprovação do dolo é pressuposto para tipificação da conduta e aplicação das sanções. STJ, AIA 30/AM, Rel. Min. Teori Albino Zavascki, Corte Especial, DJe 28/09/2011.
} 
d) coerência administrativa (art. 30 da LINDB): as autoridades públicas devem atuar para aumentar a segurança jurídica na aplicação das normas, inclusive por meio de regulamentos, súmulas administrativas e respostas a consultas. Os instrumentos previstos no caput do art. 30 terão caráter vinculante em relação ao órgão ou entidade a que se destinam, até ulterior revisão.

Verifica-se, especialmente no último pilar mencionado acima, que a coerência administrativa, inerente ao Estado Democrático de Direito, é reforçada com a alteração promovida na LINDB.

Além de garantir a segurança jurídica e a isonomia na interpretação e na aplicação do Direito, a atuação coerente do gestor público, com a aplicação das mesmas soluções jurídicas aos casos semelhantes, configura importante instrumento de proteção pessoal contra eventual responsabilização posterior perante os órgãos de controle.

\section{O DeVer de CoerênCIA NA AdMinistração Pública}

No âmbito do Estado Democrático de Direito, a Administração Pública está subordinada não apenas às leis, mas também aos princípios jurídicos, naquilo que se convencionou denominar de princípio da juridicidade. ${ }^{6}$ É possível afirmar, atualmente, que o fundamento do Direito Administrativo é a efetivação dos direitos fundamentais, o que demonstra a impossibilidade de atuações administrativas completamente livres, caprichosas e autoritárias.

A vinculação da Administração Pública relaciona-se não apenas com os atos externos, provenientes de outros Poderes (leis e decisões judiciais), mas, também, com os seus próprios atos administrativos (individuais e normativos) e práticas administrativas.

Quanto à origem, a vinculação administrativa pode ser dividida em duas espécies (OTERO, 2003, p. 381-382):

a) heterovinculação (ou vinculação externa): a vinculação decorre de atos externos à Administração Pública (ex.: Constituição, leis e decisões judiciais); e

b) autovinculação (ou vinculação interna): a vinculação decorre dos próprios atos e condutas da Administração (ex.: atos administrativos individuais e normativos, praxe administrativa, promessas administrativas, contratos). ${ }^{7}$

No Brasil, a concepção de heterovinculação administrativa possui ampla aceitação, notadamente pela consagração dos princípios constitucionais da

\footnotetext{
${ }^{6}$ Sobre a expressão, vide Paulo Otero (2003, p. 381-382).

7 Segundo Alexandre Aragão (2008, p. 02): “A teoria das autolimitações administrativas constitui, na verdade, um conjunto de instrumentos diversos, mas complementares, que visam a assegurar a razoabilidade, a coerência e a isonomia no tratamento conferido pela Administração Pública aos cidadãos, em uma expressão do Estado Democrático de Direito e do devido processo legal substancial, que vedam as iniquidades estatais".
} 
legalidade e da separação de poderes (ou funções), com a previsão de freios e contrapesos (checks and balances).

Não é novidade a afirmação de que a atuação administrativa se encontra submetida à lei, razão pela qual qualquer atividade administrativa ilegal deve ser, em regra, objeto de invalidação. É verdade, contudo, que a concepção de legalidade oitocentista, típica do Estado Liberal pós-revolucionário, tem sofrido mutações nos últimos anos para adequar-se à nova realidade imposta pelo neoconstitucionalismo e pelo Pós-positivismo. ${ }^{8}$

Dessa forma, a atuação administrativa submete-se ao controle de legalidade (juridicidade) exercido pelo Poder Judiciário (art. 5ㅇ, XXXV, da CRFB) e pelo Poder Legislativo (art. 49, V, da CRFB), inclusive com o auxílio dos Tribunais de Contas (art. 70 da CRFB).

Por outro lado, o estudo da autovinculação administrativa não recebeu no Brasil, com honrosas exceções, a necessária atenção da doutrina e da jurisprudência.

É preciso, portanto, desenvolver esse tópico, uma vez que a ideia de que as pessoas não podem atuar de forma contraditória e incoerente deve ser aplicada não apenas ao setor privado, mas, também, ao setor público.

Não é razoável conceber que a Administração Pública exerça suas atividades de forma aleatória e irracional, o que acarretaria insegurança jurídica e colocaria em risco a efetividade dos direitos fundamentais. A previsibilidade gerada pela atuação administrativa coerente é uma exigência do Estado Democrático de Direito, bem como dos princípios da segurança jurídica, da razoabilidade e da isonomia.

A ideia da autovinculação administrativa (Selbstbindung) surge na Alemanha no século XIX, inicialmente atrelada ao princípio da igualdade no âmbito da aplicação administrativa da lei, com o objetivo de evitar o cometimento de arbitrariedades no exercício da discricionariedade administrativa. ${ }^{9}$

Posteriormente, a ideia de autovinculação administrativa foi conectada, também, com o princípio da proteção da confiança legítima, defendendo os cidadãos contra caprichos e arbitrariedades do Poder Público, notadamente no campo das promessas estatais descumpridas ou da revogação arbitrária de atos administrativos. ${ }^{10}$

\footnotetext{
${ }^{8}$ Em razão dos limites do presente trabalho, não é possível aprofundar os termos "neoconstitucionalismo" e "Pós-positivismo", razão pela qual remetemos o leitor para a obra de Rafael Carvalho Rezende Oliveira (2010).

${ }^{9}$ Hartmut Maurer (2006, p. 706), ao tratar da autovinculação administrativa no Direito Alemão, afirma que a Administração infringe o princípio da igualdade quando se desvirtua de sua prática administrativa sem fundamento jurídico justificador. Atualmente, a autovinculação é reconhecida, com algumas peculiaridades em relação à concepção alemã, no âmbito da União Europeia (DÍEZ SASTRE, 2008, p. 176-181 e 210-220). ${ }^{10}$ Sobre a aplicação do princípio da proteção da confiança legítima no Direito Administrativo, vide Oliveira (2013, p. 163-189).
} 
A autovinculação administrativa não acarreta benefícios apenas para os particulares. A própria Administração Pública aufere vantagens com a sua atuação coerente e não contraditória, tais como: a celeridade da resposta às demandas repetitivas; a redução da litigiosidade; a diminuição das incertezas, dos riscos e dos custos das relações jurídico-administrativas; e a maior aceitação dos particulares às suas decisões e, por consequência, o reforço da legitimidade de sua atuação. ${ }^{11}$

A autovinculação administrativa pode decorrer de atividades ou de condutas administrativas diversas, tais como os atos administrativos normativos, os atos internos, as práticas administrativas continuadas, os atos individuais, as promessas administrativas etc.

Em razão das diversas possibilidades de autovinculação, a doutrina tem apresentado classificações distintas para a autovinculação administrativa. Silvia Díez Sastre (2008, p. 190-191), por exemplo, apresenta três classificações sobre o instituto, a partir de três critérios, a saber: ${ }^{12}$

1) Classificação quanto à estrutura:

1.a) autovinculação relacional: trata-se da autovinculação que decorre dos atos administrativos normativos e da prática administrativa, exigindo-se tratamento idêntico entre casos semelhantes, em razão do princípio da igualdade; e

1.b) autovinculação não relacional: relaciona-se com os princípios da boa-fé e da proteção da confiança que demanda coerência dentro da mesma relação jurídica, inexistindo, aqui, a necessidade de comparações entre relações jurídicoadministrativas envolvendo pessoas diversas.

2) Classificação quanto ao tempo e ao espaço:

2.a) autovinculação horizontal: ocorre a partir de atos administrativos editados em processos e momentos distintos; $\mathrm{e}$

2.b) autovinculação vertical: envolve atos editados dentro do mesmo processo administrativo ou da mesma sequência espacial e temporal.

3) Classificação quanto à evolução do conceito de autovinculação:

3.a) autovinculação em sentido estrito: encontra fundamento no princípio da igualdade, aplicando-se o mesmo tratamento jurídico aos casos semelhantes; e

3.b) autovinculação em sentido amplo: fundamenta-se não apenas no princípio da igualdade, mas, também, nos princípios da boa-fé e da proteção da confiança para proteger as pessoas contra os caprichos e a incoerência do Estado, seja no tratamento isonômico entre pessoas em situações fático-jurídicas semelhantes, seja na proteção da boa-fé e da confiança jurídicas dos administrados em relação às promessas, aos atos e às práticas administrativas.

Tradicionalmente, a autovinculação mantém relação intensa com a discricionariedade administrativa, funcionando como uma contenção de

\footnotetext{
${ }^{11}$ De forma semelhante, vide Paulo Modesto (2010, p. 07).

${ }^{12}$ Sobre o tema, vide, também Modesto (2010, p. 07).
} 
eventuais arbítrios por parte dos agentes públicos que exercem escolhas e valorações administrativas a partir da legislação (DÍEZ SASTRE, 2008, p. 203-206).

Vale dizer: a função principal da autovinculação é limitar a discricionariedade administrativa a partir dos princípios da igualdade, da boa-fé e da proteção da confiança legítima. A margem de liberdade reconhecida pelo legislador ao administrador público para eleger o melhor caminho administrativo na satisfação do interesse público não significa um cheque em branco para adoção de medidas desproporcionais, desiguais e contrárias à boa-fé. É necessário garantir que a atuação administrativa seja coerente e não contraditória no Estado Democrático de Direito.

Apesar de sua ligação inicial com a atuação administrativa discricionária, a ideia de autovinculação, posteriormente, foi alargada para abranger, não livre de controvérsias doutrinárias, as atuações vinculadas, as atividades prestacionais e as relações de sujeição especial envolvendo a Administração Pública e os administrados.

Cabe destacar que a autovinculação não significa o engessamento administrativo e deve ser concebida de forma relativa (e não absoluta). Isto porque a autovinculação envolve a tensão entre a busca de continuidade e de previsibilidade da ação administrativa, por um lado, e a necessidade de inovação e de flexibilidade por parte da Administração para atender às mutações sociais, tecnológicas, políticas, econômicas e culturais (PIELOW, 1997, p. 51).

Nos casos devidamente motivados, a Administração pode alterar a sua interpretação sobre determinadas normas jurídicas, aplicando-se, em regra, a nova orientação aos casos futuros semelhantes, com o objetivo de resguardar a segurança jurídica e a boa-fé dos administrados.

Em suma, no Estado Democrático de Direito pressupõe coerência na atuação estatal, afigurando-se indesejada a conduta contraditória nas relações jurídicas com os cidadãos.

Em consequência, nos processos administrativos ou nas relações jurídicas semelhantes, ainda que envolvam particulares diversos, a Administração deve aplicar tratamento isonômico e coerente.

É possível afirmar que o dever de coerência administrativa fundamenta-se, ao menos, nos seguintes princípios constitucionais:

a) princípio da igualdade: os casos semelhantes envolvendo particulares diversos devem ser tratados de forma isonômica, sendo vedada a discriminação desproporcional entre pessoas que se encontram em situações fáticas e jurídicas similares;

b) princípios da segurança jurídica, boa-fé e proteção da confiança legítima: a previsibilidade, a lealdade e a coerência da ação administrativa, com a dispensa de tratamento uniforme aos casos semelhantes, garante segurança jurídica e protege a boa-fé e as expectativas legítimas dos particulares; 
c) princípios da razoabilidade e proporcionalidade: o respeito aos seus próprios precedentes evita a prática de arbitrariedades administrativas;

d) princípio da eficiência: a atuação coerente da Administração tem o potencial de desestimular a litigância administrativa e a judicialização da questão decidida, bem como de agilizar a atividade administrativa.

Além dos argumentos constitucionais, a necessidade de coerência e previsibilidade nas atividades administrativas é uma imposição da legislação infraconstitucional.

Nesse sentido, por exemplo, em âmbito federal, o art. $2^{\circ}$, parágrafo único, XIII, da Lei 9.784/1999 dispõe que a interpretação da norma administrativa deve ser realizada da forma que melhor garanta o atendimento do fim público a que se dirige, "vedada aplicação retroativa de nova interpretação".

A partir da norma em comento, é possível perceber a preocupação do legislador federal com o respeito às interpretações administrativas que foram implementadas para resolver casos passados, impedindo a retroatividade de novas interpretações, resguardando a autoridade dos precedentes já editados.

É preciso destacar que, a partir da interpretação sistemática do ordenamento jurídico, a vedação da retroatividade da nova interpretação administrativa fundamenta-se na necessidade de proteção da boa-fé e da confiança legítima do administrado, que não pode ser surpreendido com a alteração da interpretação da Administração. Por esta razão, entendemos que nada obsta a retroatividade da nova interpretação administrativa desde que esta seja favorável aos administrados. ${ }^{13}$

A preocupação com a coerência na ação administrativa, evitando mudanças repentinas e sucessivas de interpretação, pode ser encontrada, ainda, no art. 50, VII da Lei 9.784/1999 que exige a motivação, com indicação dos fatos e dos fundamentos jurídicos, dos atos administrativos que "deixem de aplicar jurisprudência firmada sobre a questão ou discrepem de pareceres, laudos, propostas e relatórios oficiais".

Mencione-se, ainda, o Código de Processo Civil (CPC/2015) que consagrou a teoria dos precedentes judiciais, com adaptações do seu modelo originário da Common Law, bem como a necessidade de uniformização jurisprudencial, o que impacta, inclusive, nos processos administrativos. Isto porque o art. 15 do CPC/2015 dispõe que "na ausência de normas que regulem processos eleitorais, trabalhistas ou administrativos, as disposições deste Código lhes serão aplicadas supletiva e subsidiariamente".

A exigência de coerência administrativa foi reforçada com o art. 30, caput e parágrafo único, da LINDB, inserido pela Lei 13.655/2018, que exige a atuação estatal orientada para aumentar a segurança jurídica na aplicação das normas, inclusive por meio de regulamentos, súmulas administrativas e respostas a

${ }^{13}$ No mesmo sentido, Rafael Valim (2010, p. 97). 
consultas, que terão caráter vinculante em relação ao órgão ou entidade a que se destinam, até ulterior revisão.

O dever de coerência estatal revela a importância do estudo dos precedentes administrativos, que, tradicionalmente, não recebia maior atenção da doutrina tradicional, sendo possível incluí-los no rol das fontes do Direito Administrativo. ${ }^{14}$

A efetividade do princípio da segurança jurídica e da garantia de coerência estatal depende, assim com o respeito da ordem jurídica em sua integralidade, da melhoria da gestão pública, mas, também, da organização e da autonomia da advocacia pública.

Conforme será demonstrado a seguir, os advogados públicos representam os primeiros escudos da sociedade contra atuações arbitrárias dos gestores.

\section{O Papel da Advocacia Pública na Efetividade da COERÊNCIA ESTATAL}

A advocacia pública, destacada no texto constitucional como função essencial à Justiça (arts. 131 e 132 da CRFB), é responsável pelo controle interno e defesa da juridicidade dos atos estatais, garantindo aos administrados uma gestão pública dentro dos parâmetros fixados no ordenamento jurídico.

As atividades são variadas, envolvendo, por exemplo, a defesa das entidades estatais em ações judiciais, a propositura de ações judiciais de interesse municipal, a análise de minutas de editais e contratos administrativos, a emissão de pareceres sobre assuntos controversos e a orientação jurídica para os gestores.

A qualidade da atuação do advogado público e a sua caracterização como advogado de Estado - e não de governo -, depende de uma série de fatores, mas, primordialmente, da sua autonomia técnica, administrativa e financeira do próprio órgão jurídico, características indispensáveis à defesa imparcial dos atos e contratos municipais.

Nesse contexto, é possível afirmar a essencialidade da advocacia pública para preservação do Estado Democrático de Direito, com destaque para a efetivação dos princípios da segurança jurídica, da isonomia e da eficiência.

A atuação coerente e isonômica da Administração Pública, evitando a edição de atos contraditórios e o tratamento desigual entre pessoas inseridas em contextos fático-jurídicos semelhantes, depende, em larga medida, da atuação da advocacia pública que, por essa razão, deve ter assegurada a sua independência funcional.

Apenas os advogados públicos independentes são capazes de orientar os gestores públicos, com a emissão de opiniões técnicas e imparciais. Não se trata

14 De nossa parte, consideramos o precedente administrativo como a norma jurídica retirada de decisão administrativa anterior, válida e de acordo com o interesse público, que, após decidir determinado caso concreto, deve ser observada em casos futuros e semelhantes pela Administração Pública. Sobre o tema, Oliveira (2018, p. 95). 
aqui, frise-se, de atuação binária na definição da decisão estatal a ser adotada diante de determinado caso concreto, mas, sobretudo, da demonstração dos riscos e das possíveis vias decisórias colocadas à disposição do gestor público.

É fundamental não confundir a atuação da advocacia pública com a função do gestor público. A decisão é de competência exclusiva da autoridade competente, eleita ou nomeada, para o exercício das funções político-administrativas decisórias, não cabendo ao advogado público, inclusive por falta de legitimidade e de atribuição legal, compartilhar ou substituir a decisão do gestor.

Não por outra razão, criticamos a tese que pretende imputar a responsabilidade ao advogado público que, no exercício da função consultiva, emite parecer que é adotado pela autoridade como fundamento de sua decisão.

Segundo o STF, no caso dos pareceres vinculantes, seria possível a responsabilização solidária entre o parecerista e o administrador, uma vez que o parecer favorável, na visão da Corte, configuraria pressuposto de perfeição do ato, havendo a "partilha do poder de decisão". Em relação aos demais pareceres, com caráter opinativo, o parecerista responde apenas em caso de culpa grave (erro grosseiro) ou dolo ${ }^{15}$.

De nossa parte, sustentamos que a responsabilidade pela emissão do parecer, vinculante ou não, somente é possível quando comprovado erro grosseiro ou o dolo do parecerista, tendo em vista os seguintes argumentos (OLIVEIRA, 2019, p. 544-545):

a) o dever de administrar cabe à autoridade administrativa, e não ao consultor jurídico, sob pena de violação ao princípio da segregação de funções;

b) existem diversas interpretações jurídicas que podem ser razoavelmente apresentadas em cada situação concreta, não sendo possível responsabilizar o advogado público que apresentou interpretação razoável;

c) inviolabilidade do advogado, público ou privado, que responde apenas nos

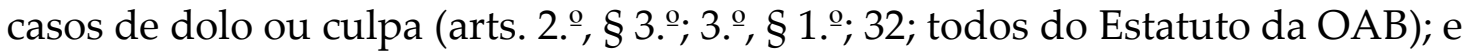

d) a responsabilidade do advogado público, sem a devida comprovação do erro grosseiro ou do dolo, viola o princípio da eficiência e o art. 28 da LINDB, pois a responsabilização indiscriminada, sem a perquirição da má-fé ou dolo, faz com que o advogado público atue com receio, sem pensar na melhor decisão a ser

\footnotetext{
15 STF, Tribunal Pleno, MS 24.631/DF, Rel. Min. Joaquim Barbosa, DJe-18 01.02.2008, Informativo de Jurisprudência do STF n. 475. Do mesmo modo, o TCU já afirmou que o parecer jurídico em processo licitatório, emitido na forma do parágrafo único do art. 38 da Lei 8.666/1993, não constitui ato meramente opinativo e pode levar à responsabilização do emitente (TCU, Plenário, Acórdão 1.337/11, Rel. Min. Walton Alencar Rodrigues, 25.05.2011, Informativo de Jurisprudência sobre Licitações e Contratos do TCU n. 64). Em outra oportunidade, no entanto, o TCU entendeu ser necessária a caracterização de erro grosseiro ou inescusável, com dolo ou culpa, para responsabilização de parecerista jurídico em processo licitatório (TCU, Acórdão 1.857/11, Rel. Min. André Luis de Carvalho, 13.07.2011, Informativo de Jurisprudência sobre Licitações e Contratos do TCU n. 71). Sobre a distinção entre pareceres facultativos, obrigatórios e vinculantes, vide: CHAPUS, Réné. Droit Administratif General. 15. ed. Paris: Montcherestien, 2001. t. I, p. $1113-1115$
} 
tomada à luz da eficiência, mas apenas na possibilidade de sofrer sanções por suas opiniões (seria mais conveniente para o advogado negar a prática de atos para evitar a sua responsabilização).

A relevância da advocacia pública na efetivação do dever de coerência administrativa foi diagnosticada por Diogo de Figueiredo Moreira Neto (1999, p. 21):

Compete ao Procurador do Estado e do Distrito Federal, no desempenho apropriado desse dever constitucional de aperfeiçoamento da ordem jurídica, aconselhar, persuadir e induzir os agentes políticos a adotarem, em suas respectivas unidades federadas, a técnica dos Pareceres vinculantes, para evitar a tomada de decisões administrativas ruinosas para o Estado.

De forma semelhante, Marcos Juruena Villela Souto (2004, p. 62) destaca a importância da advocacia pública fortalecida para efetividade da democracia e do Estado de Direito: ${ }^{16}$

Em síntese, a ninguém - salvo a governos totalitários e/ou corruptos - pode interessar uma Advocacia Pública enfraquecida ou esvaziada.

A democracia e o Estado de Direito só se fortalecem se houver sólidas e não fragmentadas instituições voltadas para o controle da legalidade, o que exige a garantia constitucional de um corpo permanente, profissionalizado, bem preparado, protegido $\mathrm{e}$ remunerado, sem riscos de interferências políticas indevidas no exercício de funções técnicas e despolitizadas".

De acordo com Gustavo Binenbojm (2010, p. 37-38), a singularidade da advocacia pública pode ser demonstrada a partir de três possibilidades e perspectivas: a) atuação prévia: é a única carreira jurídica que atua previamente à configuração das políticas públicas; b) atuação sistêmica: tem a visão sistêmica dos limites e das possibilidades relacionadas às políticas públicas, o que permite opinar sobre correção de rumos, com o objetivo de evitar efeitos colaterais indesejados; e c) atuação proativa: a advocacia pública pode atuar proativamente na prevenção de litígios.

\footnotetext{
${ }^{16}$ De forma semelhante, José Afonso da Silva (2002, p. 284) sustenta: “A Advocacia Pública assume, no Estado Democrático de Direito, mais do que uma função jurídica de defesa dos interesses patrimoniais da Fazenda Pública, mais até mesmo do que a defesa do princípio da legalidade, porque lhe incumbe igualmente e veementemente a defesa da moralidade pública".
} 
No exercício de sua missão institucional, a advocacia pública deve zelar pela coerência administrativa, o que revela a necessidade de emissão de pareceres e outras formas de manifestação jurídica, inclusive na esfera judicial, que garantam o respeito aos precedentes judiciais e administrativos.

A consagração dos precedentes judiciais no art. 927 do CPC/2015 e a sua vinculação à Administração Pública demonstram a relevância da atuação da advocacia pública na preservação da estabilidade, da integridade e da coerência do sistema jurídico.

Considerada como advocacia de Estado e não de governo, a advocacia pública possui o dever institucional de garantir, de forma preventiva e/ou repressiva, a juridicidade dos atos estatais.

No exercício da defesa judicial da Administração Pública, a advocacia pública deve alterar a tradicional cultura da atuação beligerante, acostumada com o manejo de recursos e impugnações contra decisões judiciais que aplicam teses consolidadas.

É preciso repensar a gestão de acervos de massa, bem como a estratégia em casos relevantes e estratégicos para o interesse público, com a adoção de medidas capazes de otimizar a atuação dos advogados públicos, cabendo destacar, por exemplo: a) utilização de novas tecnologias para administração eficiente do acervo; b) a previsão e a constante verificação de dispensas recursais em casos semelhantes e com teses consolidadas nos tribunais; c) a elaboração de parâmetros normativos para tentativas de acordos em casos repetidos ou estratégicos, inclusive com o fomento à instituição de câmaras de conciliação no âmbito da própria Administração para evitar judicializações desnecessárias.

A atuação eficiente da advocacia pública na esfera judicial acarreta consequências positivas não apenas aos envolvidos na lide, partes, magistrados e Ministério Público, mas à coletividade, que passa a enxergar a Administração Pública como instituição séria e pautada pela busca da eficiência.

Não apenas na atuação contenciosa, mas, especialmente, na função consultiva, eminentemente preventiva, a advocacia pública deve pautar a sua atuação pela busca de maior segurança jurídica e coerência estatal.

O objetivo não é apenas o de diminuir a judicialização das controvérsias administrativas, mas, garantir a apresentação de soluções jurídicas uniformes para casos semelhantes, exigência extraída dos princípios da segurança jurídica, da boa-fé, da proteção da confiança legítima e da isonomia.

No exercício do controle interno, os advogados públicos devem orientar a respectiva Administração Pública com a apresentação da interpretação jurídica adequada sobre os atos estatais.

Nesse ponto, a atuação da advocacia pública não deve restringir-se às interpretações formalistas, com fundamento na legalidade estrita. 
A partir da concepção do princípio da juridicidade e, como consequência, da necessidade de submissão dos atos estatais não apenas ao princípio da legalidade, mas, também, aos demais princípios constitucionais, expressos ou implícitos, é imperioso que os advogados públicos, na interpretação administrativa, levem em consideração os precedentes administrativos e judiciais vinculantes.

Quanto aos precedentes administrativos, a advocacia pública deve levar em consideração as orientações jurídicas pretéritas em casos semelhantes, com o intuito de manter a coerência interpretativa dos dispositivos constitucionais, legais e regulamentares.

Igualmente, os advogados públicos devem verificar se os atos e as decisões estatais submetidos à consulta jurídica são coerentes com as atuações anteriores da Administração Pública em casos semelhantes.

Inexistindo fato relevante e motivado para alteração ou superação do precedente administrativo, os membros da advocacia pública devem zelar pelo respeito do precedente que decidiu questão semelhante no âmbito daquela Administração.

A coerência estatal no exercício da atividade administrativa depende, também, do respeito aos precedentes judiciais vinculantes.

Isso porque a atuação administrativa contrária aos precedentes judiciais vinculantes colocaria em risco, conforme já destacado, os princípios da igualdade, da segurança jurídica e da proteção da confiança legítima, abrindo-se caminho à judicialização e ao desfazimento da ação administrativa, sem olvidar a potencial responsabilização do gestor público.

Ao lado da atuação passiva, consistente no recebimento de consultas administrativas específicas ou no exercício da defesa judicial da entidade administrativa, a advocacia pública deve pautar, de forma crescente, a sua atuação pela prevenção e proatividade, com a edição de orientações ou súmulas administrativas, a busca por soluções consensuais de conflitos e, se for o caso, a propositura de ações judiciais com o objetivo de evitar danos, restaurar a juridicidade e ressarcir eventuais prejuízos ao erário.

É verdade que a preocupação com a atuação da advocacia pública na garantia da efetividade das decisões dos tribunais superiores no âmbito dos processos administrativos não representa novidade.

Em âmbito federal, compete à AGU "unificar a jurisprudência administrativa, garantir a correta aplicação das leis, prevenir e dirimir as controvérsias entre os órgãos jurídicos da Administração Federal", podendo editar, inclusive, enunciados de súmula administrativa, resultantes de jurisprudência iterativa dos Tribunais (art. 4⿳⺈, XI e XII, da LC 73/1993).

Com o objetivo de garantir a uniformidade da interpretação administrativa, os membros efetivos da AGU não podem contrariar súmula, parecer normativo ou 
orientação técnica adotada pelo Advogado-Geral da União (art. 28, II, da LC 73/1993). ${ }^{17}$

$\mathrm{O}$ art. 40, § $1^{\circ}$, da LC 73/1993 dispõe que o parecer do Advogado-Geral da União, aprovado e publicado juntamente com o despacho presidencial, vincula a Administração Federal, cujos órgãos e entidades ficam obrigados a lhe dar fiel cumprimento.

Ademais, a súmula da AGU tem caráter obrigatório para seus respectivos órgãos jurídicos, inclusive aqueles que atuam nas autarquias e fundações públicas federais, na forma do art. 43 da LC 73/1993. Com fundamento no referido dispositivo legal, o art. 2o ${ }^{\underline{o}}$ do Decreto 2.346/1997, que consolida normas de procedimentos a serem observadas pela Administração Pública Federal em razão de decisões judiciais, determina que, após firmada a jurisprudência pelos Tribunais Superiores, a Advocacia-Geral da União expedirá súmula a respeito da matéria, cujo enunciado deve ser publicado no Diário Oficial da União.

A partir das súmulas da própria AGU, o Advogado-Geral da União poderá dispensar a propositura de ações ou a interposição de recursos judiciais (art. $3^{\circ}$ do Decreto 2.346/1997).

A preocupação da AGU com a coerência administrativa pode ser demonstrada, também, pela instituição da Câmara de Conciliação e Arbitragem da Administração Federal (CCAF), órgão integrante da AGU, com competência, por exemplo, para dirimir, por meio de conciliação, as controvérsias entre órgãos e entidades da Administração Pública Federal, bem como entre estes e a Administração Pública dos Estados, do Distrito Federal e dos Municípios, na forma do art. 18, III, do Anexo I do Decreto 7.392/2010.

Mencione-se, ainda, que, no processo administrativo fiscal federal, é vedado aos órgãos de julgamento afastar a aplicação ou deixar de observar tratado, acordo internacional, lei ou decreto, sob fundamento de inconstitucionalidade, salvo (art. 26-A, caput, e $\S 6^{\circ}$, I e II, do Decreto 70.235/1972, alterado pela Lei 11.941/2009): a) se o ato tiver sido declarado inconstitucional por decisão definitiva plenária do STF; b) se o ato fundamentar crédito tributário objeto de: b.1) dispensa legal de constituição ou de ato declaratório do Procurador-Geral da Fazenda Nacional, na forma dos arts. 18 e 19 da Lei 10.522/2002; b.2) súmula da AGU, na forma do art. 43 da LC 73/1993; ou b.3) pareceres do Advogado-Geral da União aprovados pelo Presidente da República, na forma do art. 40 da LC 73/1993.

Aliás, no processo administrativo fiscal, a necessidade de coerência administrativa justifica não apenas a edição de súmulas administrativas por parte do Conselho Administrativo de Recursos Fiscais - CARF, órgão colegiado, paritário, integrante da estrutura do Ministério da Fazenda (art. 25, II do Decreto

17 A vedação também se aplica aos Procuradores do Banco Central do Brasil (art. 17-A, II, da Lei 9.650/1998, inserido pela Medida Provisória 2.229-43/2001). 
70.235/1972, alterado pela Lei 11.941/2009), mas o respeito aos precedentes administrativos do próprio Conselho.

É possível perceber, portanto, que o ordenamento jurídico, antes do CPC/2015, já demonstrava preocupação com a aplicação coerente da jurisprudência e das orientações administrativas no exercício da advocacia pública.

Contudo, esse papel é reforçado com o advento do CPC/2015, uma vez que os precedentes vinculantes previstos no seu art. 927 devem ser observados pelas autoridades administrativas, independentemente da existência de súmula ou orientação do órgão jurídico responsável pela consultoria do respectivo ente federado. ${ }^{18}$

Em verdade, o órgão jurídico pode emitir orientação específica, inclusive por meio de súmula, para o administrador público e demais membros do órgão jurídico, com o objetivo de reiterar e esclarecer a necessidade de cumprimento do precedente judicial, mas essa conduta não é condição necessária para que o precedente judicial seja observado pela Administração.

\section{CONClUSÃo}

A Conforme destacado ao longo do texto, a sociedade contemporânea ou "pós-moderna" é fortemente marcada pela complexidade, pluralidade e incerteza, o que incrementa o desafio de implementação de uma atuação estatal coerente e em compasso com os princípios da segurança jurídica, da boa-fé, da proteção da confiança legítima e da isonomia.

O tratamento isonômico e coerente dos administrados é dever do gestor público, cujo exercício pressupõe a existência de órgão da advocacia pública capaz de emitir as orientações jurídicas necessárias à tomada das decisões.

A advocacia pública, instituição permanente, autônoma e especializada, composta por membros escolhidos por mérito e dotadas de garantias institucionais próprias, revela-se órgão estatal essencial ao Estado Democrático de Direito.

No rol de suas atribuições, ganha relevo, atualmente, o papel de garantir a coerência dos atos estatais, com o respeito aos precedentes administrativos e judiciais vinculantes, evitando a atuação administrativa esquizofrênica e em descompasso com o interesse público.

\footnotetext{
${ }^{18}$ Nesse sentido, a Portaria MF 152/2016 promoveu recente alteração no regimento interno do Conselho Administrativo de Recursos Fiscais - CARF (art. 62, $\S 2^{\circ}$ ) para exigir que os seus relatores respeitassem o que já foi pacificado na jurisprudência do STF e STJ em sede dos recursos extraordinários e recursos especiais repetitivos (arts. 1.036 a 1.041 do CPC/2015). Entendemos, contudo, que a vinculação da Administração Pública deve englobar todos os precedentes vinculantes indicados no art. 927 do CPC (OLIVEIRA, 2018, p. 146-154).
} 


\section{REFERÊNCIAS}

ARAGÃO, Alexandre Santos de. Teoria das autolimitações administrativas: atos próprios, confiança legítima e contradição entre órgãos administrativos. In: Revista Eletrônica de Direito Administrativo Econômico. Salvador, IBDP, n.14, maio/julho, 2008.

ARNAUD, André-Jean. Governar sem fronteiras: entre globalização e pósglobalização. Rio de Janeiro: Lumen Juris, 2007.

BAUMAN, Zygmunt. Modernidade líquida. Rio de Janeiro, Jorge Zahar, 2001.

BECK, Ulrich. La société du risque: Sur la voie d'une autre modernité. Paris: Editions Flammarion, 2001.

BINENBOJM, Gustavo. A advocacia pública e o Estado Democrático de Direito. Revista Brasileira de Direito Público. Belo Horizonte, v. 8, n. 31, out. 2010.

CHAPUS, Réné. Droit Administratif General, t. I, 15. ed. Paris: Montcherestien, 2001.

CHEVALIER, Jacques. O Estado Pós-Moderno. Belo Horizonte: Fórum, 2009.

DÍEZ SASTRE, Silvia. El precedente administrativo: fundamentos y eficácia vinculante. Madrid: Marcial Pons, 2008.

GIDDENS, Anthony. Modernidade e identidade. Rio de Janeiro: Jorge Zahar, 2002.

GROSSI, Paolo. Mitologias jurídicas da modernidade. 2. ed. Florianópolis: Fundação Boiteux, 2007.

MAURER, Hartmut. Direito Administrativo Geral. Barueri: Manole, 2006.

MODESTO, Paulo. Autovinculação da Administração Pública. Revista

Eletrônica de Direito do Estado. Salvador, Instituto Brasileiro de Direito Público, n. 24 , out./dez., 2010. 
MOREIRA NETO, Diogo de Figueiredo. Advocacia pública e o princípio da eficiência. Interesse Público. Belo Horizonte, v. 1, n. 4, out. 1999.

OLIVEIRA, Rafael Carvalho Rezende. A constitucionalização do direito administrativo: o princípio da juridicidade, a releitura da legalidade administrativa e a legitimidade das agências reguladoras. 2. ed. Rio de Janeiro: Lumen Juris, 2010.

OLIVEIRA, Rafael Carvalho Rezende. Princípios do Direito Administrativo. 2a ed., São Paulo: Método, 2013.

OLIVEIRA, Rafael Carvalho Rezende. Precedentes administrativos, São Paulo: Método, 2018.

OLIVEIRA, Rafael Carvalho Rezende. Curso de Direito Administrativo. 7. ed. São Paulo: Método, 2019.

OTERO, Paulo. Legalidade e Administração Pública: o sentido da vinculação administrativa à juridicidade. Coimbra: Almedina, 2003.

PIELOW, Johann-Cristian. Integración Del ordenamiento jurídico:

autovinculaciones de La Administración. In: MUÑOZ, Guillermo Andrés; SALOMONI, Jorge Luis. Problemática de La administración contemporânea: una comparación europeo-argentina. Buenos Aires: Ad-Hoc, 1997.

ROMANO, Santi. O ordenamento jurídico. Florianópolis: Fundação Boiteux, 2008.

SILVA, José Afonso. A advocacia pública e o Estado Democrático de Direito. Revista de Direito Administrativo. Rio de Janeiro, 230, out./dez. 2002.

SOUTO, Marcos Juruena Villela. O papel da advocacia pública no controle da legalidade da Administração. Interesse Público. Belo Horizonte, v. 6, n. 28, nov. 2004, p. 62.

VALIM, Rafael. O princípio da segurança jurídica no Direito Administrativo brasileiro. São Paulo: Malheiros, 2010. 